\title{
Effects of Short-Necked Clam Phospholipids on the Growth of Prawn ${ }^{* 1}$
}

\author{
Akio KanazawA ${ }^{* 2}$, Shin-ichi TeshimA*2, Shigeru ToKIWA ${ }^{* 2}$, \\ Minoru ENDO*2, and Fatma Aly ABDEL RAZEK*3 \\ (Received March 7, 1979)
}

\begin{abstract}
To clarify the growth-promoting effects of phospholipids, the prawn, Penaeus Japonicus, was maintained on various test diets containing a $7 \%$ level of pollack liver oil (PLO) and a $1 \%$ level of one of the following lipids: total lipids, acetone-soluble lipids (or neutral lipids), acetoneinsoluble lipids (or polar lipids), lecithin fraction, cephatin fraction, sphingomyelin-glycolipids (1:1), fatty acids of lecithin isolated from the short-necked clam, Tapes philippinarum, commercial phospholipids, animal cephalin, egg lecithin, and soybean lecithin.

The highest weight gain was attained on the diet containing $7 \%$ PLO and $1 \%$ Tapes lecithin fraction. However, the fatty acids of Tapes lecithin did not exert such a growth-promoting effect. Also, soybean lecithin and egg lecithin had no effect. Tapes cephalin and animal cephalin were effective for the improvement of weight gain to some extent, but the growth-promoting effect of the two types of cephalin was not so as high as that of Tapes lecithin.

These results suggest that the growth-promoting effect of Tapes lecithin is probably due to certain effects of the molecular form of Tapes lecithin itself.
\end{abstract}

Recent advances in the nutritional studies on lipids have shown the unique aspects of essential fatty acids (EFA) requirements in fish ${ }^{1,2)}$ and crustaceans ${ }^{3 !}$. The growth of crustaceans is affected not only with the level of dietary lipids, but also with the kind of lipids. Generally, a superior growth is attained on the diets containing marine types of lipids such as pollack liver oil (PLO) rich in $\omega 3$ highly unsaturated fatty acids (HUFA), 20:5 53 and 22: $6 \omega 3$, as observed in fish.

Previously, we have observed that a superior weight gain of the prawn, Penaeus japonicus, was attained on the diet containing the lipids of short-necked clam (Tapes lipids) rather than on that containing PLO $^{4}$. Since Tapes lipids contained abundance of phospholipids (more than $65 \%$ of total lipids), some components of Tapes phospholipids were assumed to exert a high nutritive value for the prawn. In the present study, hence, we intend to examine the effects of each phospholipid fraction on the growth of prawn. This paper deals with these results and discussion on the role of phospholipids in the diet of prawn.

\section{Materials and Methods}

\section{Prawn and Feeding Method}

The prawn, $P$. japonicus, $0.4-1.0 \mathrm{~g}$ in body weight, was used in this study. Feeding experiments were conducted 3 times: Experiment-I (July, 1975), Experiment-II (September, 1977), and Experiment-III (August, 1978). Fifteen or 20 prawns were maintained on each test diet in a plastic aquarium (30 liters) for 30 or 45 days at $22-25^{\circ} \mathrm{C}$. The methods for feeding and preparation of diets were the same as reported previously $^{4,5}$.

\section{Preparation of Lipid Fractions from the Short- Necked Clam}

Total lipids were extracted with chloroformmethanol-water $(2: 2: 1, \mathrm{v} / \mathrm{v})^{6}$ from the whole body of short-necked clam and then separated into neutral and polar lipids by column chromatography on Kieselgel 60 as mentioned previous$\mathrm{ly}^{71}$. In Experiment-I, total lipids were separated into acetone-soluble and acetone-insoluble lipids. Phospholipid fractions were isolated by a solvent-fractionation method ${ }^{81}$ as follows: Polar lipids (or acetone-insoluble lipids) were extracted with 10 volumes of ether after dissolving

*1 A part of this study was orally presented on the Annual Meeting of Japan. Soc. Sci. Fish., in April, 1976.

*2 Faculty of Fisheries, University of Kagoshima, 4-50-20 Shimoarata, Kagoshima 890 (金沢昭夫・手島 新一・常盤 繁・猿渡 実: 鹿児島大学水産学部).

*3 Institute of Oceanography and Fisheries, Kayed Bay, Alexandria, Egypt (ファトマ・フリ・アブデル ラジェク：エシプト海洋水産研究所). 
in a small amount of chloroform, and the ethersoluble lipids were separated into lecithin (ethanol-soluble) and cephalin (ethanol-insoluble) fractions by treatment with ethanol, whereas the ether-insoluble lipids were separated into glycolipid (pyridine-soluble) and sphingolipid (pyridine-insoluble) fractions with hot pyridine.

Soybean lecithin, egg lecithin, and animal cephalin were purchased from Tokyo Kasei Organic Chemicals Co. PLO used as lipid source of base in this study was supplied from Riken Vitamin Oil Co., Ltd. and scarcely contained polar lipids such as lecithin and cephalin.

The purities of these phospholipids were checked by thin-layer chromatography on Kieselgel G-Kieselgel $G_{254}(4: 1$, w/w) with chloroformmethanol-water $(70: 30: 5, \mathrm{v} / \mathrm{v})$ and were as follows: Tapes lecithin ( $88 \%$ ), Tapes cephalin (98\%), Tapes sphingomyelin (77\%), Tapes glycolipid $(69 \%)$, and commercial lecithin $(95-98 \%)$ and cephalin ( $95 \%$ ).

\section{Test Diet}

The composition of basal diet was the same as reported previously ${ }^{4}$. The composition of dietary lipids is listed in Table 1. The test diets were prepared by adding $1 \%$ levels of examined lipids to the diet containing $7 \%$ level of PLO and $0.5 \%$ level of cholesterol. In this study, a growth-promoting effect of the following lipids was examined; Total lipids, acetone-soluble lipids, acetone-insoluble lipids, neutral lipids, polar lipids, lecithin, cephalin, and sphingomyelin-glycolipid fractions from the short-necked clam, and commercial phospholipids, egg lecithin, soybean lecithin, and animal cephalin.

\section{Determination of Fatty Acid Composition}

After the feeding trial in Experiment-I, lipids were extracted from the whole body of prawns, and the fatty acid composition was determined by gas-liquid chromatography (GLC) on $10 \%$ DEGS ( $3 \mathrm{~m}$ long $\times 4 \mathrm{~mm}$ i.d., column temperature $190^{\circ} \mathrm{C}$ ) as mentioned previously.

\section{Results}

Table 1 shows the weight gain of prawn, $P$. japonicus, fed the test diets.

In Experiment-I, the effects of Tapes lipid fractions on the weight gain of prawn were examined by the 30 day-feeding trial using 7 test diets. The highest weight gain was attained on the diet No. 5 containing $7 \%$ PLO plus $1 \%$ Tapes lecithin fraction as lipid sources. Also, the addition of $1 \%$ levels of acetone-insoluble lipid and cephalin fractions from Tapes improved the weight gain of prawn. Whereas, acetone-soluble lipid and sphingomyelin-glycolipid fractions from Tapes did not exert such a growth-promoting effect for the prawn, P. japonicus. The results of Experiment-I indicated that Tapes phospholipids, especially lecithin fraction, were highly effective for the improvement of weight gain. Thereupon, Experiments II and III were carried out to ascertain the growth-promoting effect of Tapes phospholipids and also to examine the effects of phospholipids from the terrestrial sources on the growth of prawn.

In Experiments II and III, the highest weight gain was again attained on the diet No. 5 supplemented with Tapes lecithin fraction, and Tapes polar lipid and total lipid fractions followed to this. Animal cephalin showed a similar growthpromoting effect to that of Tapes cephalin fraction, but the two types of cephalin did not improved the weight gain so markedly as observed on Tapes lecithin in both Experiment-II and Experiment-III. The results of Experiment-III showed that soybean lecithin and egg lecithin were of no effect on the improvement of weight gain, differing from Tapes lecithin. Also, the fatty acids derived from Tapes lecithin scarcely improved the weight gain.

Tables 2 and 3 show the fatty acid composition of examined lipids. Table 4 indicates the fatty acid composition of prawn body after feeding trial in Experiment-1. Every lipid fractions from Tapes contained $16: 0(11.1-25.2 \%$ of total fatty

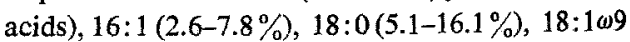
$(3.1-9.0 \%), 20: 1 \omega 9(5.1-13.0 \%), 20: 4 \omega 3(1.7-$ $13.5 \%), 20: 5 \omega 3(5.8-19.0 \%)$, and $22: 6 \omega 3(2.0-$ $13.4 \%$ ) as a major fatty acid. Although the fatty acid composition of examined lipids differed from each other, the difference was not so as great as alters the dietary levels of EFA such as 18:3 $\omega 3$, 20:5 $\omega 3$, and 22:6 $\omega 3$ in the test diets. The fatty acid composition of the prawn body did not vary so markedly according to the test diets (Table 4). Therefore, we assume that the growth-promoting effect of Tapes phospholipids is caused with certain effect of phospholipids themselve rather than with that of EFA.

\section{Discussion}

TAKEUCHI and WATANABE ${ }^{10)}$ have reported 
Table 1. Effects of phospholipids on growth of prawn, $P$. japonicus

\begin{tabular}{|c|c|c|c|c|c|}
\hline $\begin{array}{c}\text { Experi- } \\
\text { ment }\end{array}$ & $\begin{array}{l}\text { Diet } \\
\text { No. }\end{array}$ & Dietary lipid & $\begin{array}{l}\text { Feeding } \\
\text { period } \\
\text { (days) }\end{array}$ & $\begin{array}{c}\text { Number } \\
\text { of } \\
\text { prawn }\end{array}$ & $\begin{array}{c}\text { Weight } \\
\text { gain } \\
(\%)\end{array}$ \\
\hline \multirow{7}{*}{ I } & 1 & $7 \% \mathrm{PLO}^{* 1}$ & 30 & 20 & 83 \\
\hline & 2 & $7 \%$ PLO $+1 \%$ Total lipids of Tapes*2 & 30 & 20 & 90 \\
\hline & 3 & $7 \%$ PLO $+1 \%$ Acetone-soluble lipids of Tapes & 30 & 20 & 78 \\
\hline & 4 & $7 \%$ PLO $+1 \%$ Acetone-insoluble lipids of Tapes & 30 & 20 & 112 \\
\hline & 5 & $7 \%$ PLO $+1 \%$ Lecithin fr. of Tapes & 30 & 20 & 136 \\
\hline & 6 & $7 \%$ PLO $+1 \%$ Cephalin fr. of Tapes & 30 & 20 & 118 \\
\hline & 7 & $7 \%$ PLO $+0.08 \%$ Sphingomyelin-Glycolipid fr. $(1: 1)$ of Tapes & 30 & 20 & 81 \\
\hline \multirow{6}{*}{ II } & 2 & $7 \%$ PLO $+1 \%$ Total lipids of Tapes & 45 & 15 & 200 \\
\hline & 8 & $7 \%$ PLO $+1 \%$ Neutral lipids of Tapes & 45 & 15 & 157 \\
\hline & 9 & $7 \%$ PLO $+1 \%$ Polar lipids of Tapes & 45 & 15 & 213 \\
\hline & 5 & $7 \%$ PLO $+1 \%$ Lecithin fr. of Tapes & 45 & 15 & 240 \\
\hline & 6 & $7 \%$ PLO $+1 \%$ Cephalin fr. of Tapes & 45 & 15 & 165 \\
\hline & 10 & $7 \%$ PLO $+1 \%$ Cephalin (animal) & 45 & 15 & 170 \\
\hline \multirow{11}{*}{ III } & 1 & $7 \%$ PLO & 45 & 15 & 100 \\
\hline & 11 & $8 \%$ PLO & 45 & 15 & 109 \\
\hline & 2 & $7 \%$ PLO $+1 \%$ Total lipids of Tapes & 45 & 15 & 130 \\
\hline & 8 & $7 \%$ PLO $+1 \%$ Neutral lipids of Tapes & 45 & 15 & 101 \\
\hline & 9 & $7 \%$ PLO $+1 \%$ Polar lipids of Tapes & 45 & 15 & 140 \\
\hline & 5 & $7 \%$ PLO $+1 \%$ Lecithin fr. of Tapes & 45 & 15 & 160 \\
\hline & 12 & $7 \%$ PLO $+1 \%$ Fatty acids from lecithin fr. of Tapes & 45 & 15 & 106 \\
\hline & 13 & $7 \%$ PLO $+1 \%$ Lecithin (soybean) & 45 & 15 & 107 \\
\hline & 14 & $7 \% \mathrm{PLO}+1 \%$ Lecithin (egg) & 45 & 15 & 105 \\
\hline & 6 & $7 \%$ PLO $+1 \%$ Cephalin fr. of Tapes & 45 & 15 & 135 \\
\hline & 10 & $7 \%$ PLO $+1 \%$ Cephalin (animal) & 45 & 15 & 134 \\
\hline
\end{tabular}

*1 Pollack liver oil

*2 The short-necked clam, T. philippinarum

Table 2. Composition $(\%)$ of the main fatty acids constituting of lipid fractions from the shortnecked clam

\begin{tabular}{|c|c|c|c|c|c|c|c|c|c|}
\hline \multirow{2}{*}{$\begin{array}{l}\text { Fatty } \\
\text { acid }\end{array}$} & \multicolumn{8}{|c|}{$\%$ Composition of fatty acids } & \multirow[b]{2}{*}{$\begin{array}{l}\text { Glycolipid } \\
\text { fraction }\end{array}$} \\
\hline & $\begin{array}{l}\text { Total } \\
\text { lipids }\end{array}$ & $\begin{array}{c}\text { Neutral } \\
\text { lipids }\end{array}$ & $\begin{array}{l}\text { Acetone- } \\
\text { solubles }\end{array}$ & $\begin{array}{l}\text { Polar } \\
\text { lipids }\end{array}$ & $\begin{array}{l}\text { Acetone } \\
\text { insolubles }\end{array}$ & $\begin{array}{l}\text { Lecithin } \\
\text { fraction }\end{array}$ & $\begin{array}{l}\text { Caphalin } \\
\text { fraction }\end{array}$ & $\begin{array}{l}\text { Sphingo- } \\
\text { myelin } \\
\text { fraction }\end{array}$ & \\
\hline $14: 0$ & 3.1 & 3.7 & 0.8 & 2.1 & 1.6 & 3.2 & 1.1 & 3.3 & 1.1 \\
\hline $16: 0$ & 19.0 & 15.7 & 18.8 & 18.6 & 18.0 & 24.3 & 11.1 & 22.3 & 25.2 \\
\hline $16: 1$ & 5.9 & 7.8 & 5.4 & 4.1 & 5.9 & 7.0 & 2.6 & 6.3 & 4.4 \\
\hline 18:0 & 7.6 & 7.6 & 6.0 & 8.4 & 5.1 & 7.0 & 13.3 & 8.3 & 16.1 \\
\hline 18: $1 \omega 9$ & 5.8 & 8.2 & 5.9 & 4.3 & 7.3 & 7.2 & 3.1 & 9.0 & 8.1 \\
\hline $18: 2 \omega 6$ & 0.5 & 0.9 & 0.8 & 0.4 & 1.2 & 0.9 & 0.4 & 2.6 & 0.8 \\
\hline $18: 3 \omega 3$ & 0.2 & 0.5 & 1.1 & 0.2 & 1.7 & 0.1 & 0.9 & 1.0 & 1.0 \\
\hline $20: 1 \omega 9$ & 7.4 & 8.0 & 8.8 & 9.1 & 5.3 & 6.8 & 13.0 & 5.1 & 10.3 \\
\hline $20: 4 \omega 3$ & 4.2 & 3.1 & 5.3 & 2.7 & 13.5 & 1.7 & 4.7 & 4.7 & 1.7 \\
\hline $20: 5 \omega 3$ & 15.3 & 17.1 & 10.1 & 19.0 & 9.1 & 11.6 & 18.9 & 8.7 & 5.8 \\
\hline $22: 6 \omega 3$ & 13.3 & 11.0 & 13.0 & 12.5 & 11.0 & 8.2 & 8.0 & 6.4 & 2.0 \\
\hline
\end{tabular}

that the growth-promoting effect of Tapes lipids on the rainbow trout is attributable to fatty acids, especially $\omega 3$ HUFA such as $20: 5 \omega 3$ and $22: 6 \omega 3$. In the case of the rainbow trout, the HUFA was shown to give an almost similar efficiency as EFA regardless of the molecular forms such as phospholipids, triglycerides, methylesters, and free fatty acids $^{10)}$. Previously, we have shown that Tapes lipids were the most superior as lipid sources in the diet of prawn, $P$. japonicus ${ }^{4}$. The results of the 
present study indicated that the addition of Tapes phospholipids, especially lecithin fraction, to the diet containing 7\% PLO resulted in the increase in the weight gain of prawn. Since the fatty acids of Tapes lecithin fraction had not such a growthpromoting effect, we suggest that a high nutritive value of Tapes lipids is not only due to the high content of $\omega 3$ HUFA, but also to certain effects of phospholipids themselve, differing from the rainbow trout.

The present study also showed that Tapes lecithin fraction had the highest growth-promoting effect among the phospholipids examined. Since the addition of $1 \%$ Tapes lecithin to the diet containing $7 \%$ PLO scarecely elevated the

Table 3. Composition of the main fatty acids constituting PLO and commercial phospholipids

\begin{tabular}{lcccc}
\hline \multirow{2}{*}{$\begin{array}{c}\text { Fatty } \\
\text { acid }\end{array}$} & \multicolumn{4}{c}{$\%$ Composition of fatty acids } \\
\cline { 2 - 5 } & $\begin{array}{c}\text { Soybean } \\
\text { lecithin }\end{array}$ & $\begin{array}{c}\text { Egg } \\
\text { lecithin }\end{array}$ & $\begin{array}{c}\text { Animal } \\
\text { cephalin }\end{array}$ & PLO $^{* 1}$ \\
\hline 14:0 & 1.0 & 1.2 & 5.3 & 3.4 \\
$16: 0$ & 16.3 & 27.6 & 22.6 & 26.0 \\
$16: 1$ & 0.4 & 4.8 & 1.2 & 7.6 \\
$18: 0$ & 3.8 & 5.7 & 12.2 & 5.9 \\
$18: 1 \omega 9$ & 13.6 & 34.6 & 24.1 & 6.8 \\
$18: 2 \omega 6$ & 51.6 & 15.5 & 13.7 & 0.5 \\
$18: 3 \omega 3$ & 8.2 & 0.7 & 0 & 0.9 \\
$20: 1 \omega 9$ & 0.3 & 0.4 & 2.6 & 7.3 \\
$20: 4 \omega 3$ & 0.9 & 0.6 & 2.9 & 3.3 \\
$20: 5 \omega 3$ & 0.7 & 0.1 & 2.9 & 13.7 \\
$22: 6 \omega 3$ & 0 & 0 & 2.2 & 13.3 \\
\hline
\end{tabular}

*1 Pollack liver oil dietary levels of carolie and $\omega 3$ series of EFA such

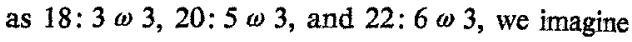
that Tapes lecithin probably exerts the growthpromoting effect for the prawn, $P$. japonicus, by taking part in the intestinal absorption and/or interorgan transport of dietary lipids and cholesterol. In fact, literatures ${ }^{11-17)}$ have suggested that in crustaceans phospholipids probably play an important role in the emulsification, absorption, and interorgan transport of lipids, of which mechanism is assumed to be different with that in mammals and other vertebrates. For example, VAN DEN OORD et al. ${ }^{11,12 !}$ have demonstrated that the gastric juice of the crab, Cancer magister, contained no bile acids but fatty acylsarcosyltaurine, comprising predominantly cis-dodec-5enoic acid conjugated with dipeptide sarcosyltaurine (DST), as an emulsifier. Later, LESTER et al. ${ }^{14)}$ have indicated that cholesterol may be absorbed from the intestine after the formation of single-phase micellar by the ternary system of cholesterol, lecithin, and DST. On the other hand, we have suggested that the principal lipid transport in the prawn, $P$. japonicus, is probably operated as a form of phospholipids, on the basis of the fact that the hemolymph lipids of this prawn contain abundance of phospholpids $(63 \% \text { of total lipids })^{16}$.

Considering the above-mentioned informations, the physiological roles of phospholipids in crustaceans seem to be interesting subject to study in future from the nutritional, physiological, and biochemical viewpoints.

Table 4. Composition (\%) of the main fatty acids of polar and neutral lipids in the prawn body after feeding trial (Experiment-I)

\begin{tabular}{|c|c|c|c|c|c|c|c|c|c|c|c|c|c|c|}
\hline \multirow{3}{*}{$\begin{array}{l}\text { Fatty } \\
\text { acid }\end{array}$} & \multicolumn{14}{|c|}{$\%$ Composition of fatty acids } \\
\hline & \multicolumn{7}{|c|}{ Polar lipid fraction } & \multicolumn{7}{|c|}{ Neutral lipid fraction } \\
\hline & 1 & 2 & $\underset{3}{\text { Diet }}$ & No. sup $_{4}$ & $\frac{1 \text { plied }}{5}$ & 6 & 7 & 1 & 2 & $\underset{3}{\text { Diet }}$ & ${ }_{4}$ No. sur & $\underset{5}{\text { oplied }}$ & 6 & 7 \\
\hline $14: 0$ & 1.2 & 0.8 & 0.9 & 1.2 & 1.2 & 1.1 & 1.1 & 2.5 & 5.5 & 2.7 & 2.0 & 2.4 & 3.0 & 2.1 \\
\hline $16: 0$ & 15.5 & 14.0 & 25.5 & 13.9 & 25.7 & 18.5 & 16.8 & 14.1 & 11.1 & 12.7 & 11.4 & 12.8 & 11.7 & 10.3 \\
\hline $16: 1$ & 4.8 & 5.7 & 8.0 & 6.8 & 7.3 & 5.7 & 4.5 & 9.4 & 6.0 & 6.7 & 8.3 & 8.4 & 6.3 & 6.7 \\
\hline $18: 0$ & 4.5 & 5.5 & 5.5 & 6.4 & 6.5 & 6.9 & 6.9 & 5.2 & 4.9 & 4.7 & 6.0 & 4.7 & 5.5 & 4.2 \\
\hline $18: 1 \omega 9$ & 24.7 & 18.0 & 17.1 & 22.2 & 23.6 & 24.6 & 22.8 & 23.3 & 21.8 & 23.5 & 20.9 & 25.5 & 22.4 & 21.5 \\
\hline $18: 2 \omega 6$ & 3.8 & 2.2 & 3.9 & 3.2 & 3.1 & 2.1 & 2.8 & 1.5 & 1.5 & 1.5 & 1.2 & 1.8 & 1.2 & 1.6 \\
\hline $18: 3 \omega 3$ & 0.3 & 0.1 & 0.1 & 0.5 & 1.7 & 0.3 & 0.2 & 0.4 & 0.3 & 0.3 & 0.4 & 0.3 & 0.3 & 0.2 \\
\hline $20: 1 \omega 9$ & 7.4 & 14.4 & 7.9 & 6.2 & 9.4 & 7.4 & 5.7 & 13.3 & 15.1 & 15.3 & 13.2 & 10.2 & 13.5 & 10.9 \\
\hline $20: 4 \omega 3$ & 0.1 & 0.1 & 0.2 & 0.1 & 0.1 & 0.2 & 0.1 & 0.1 & 0.3 & 0.2 & 0.2 & 0.2 & 0.1 & 0.1 \\
\hline $20: 5 \omega 3$ & 15.3 & 19.4 & 14.4 & 18.1 & 17.8 & 16.6 & 15.2 & 9.2 & 8.8 & 10.2 & 8.6 & 11.6 & 10.2 & 12.2 \\
\hline $22: 6 \omega 3$ & 10.1 & 11.2 & 10.0 & 10.7 & 12.4 & 11.8 & 13.3 & 4.5 & 5.9 & 5.0 & 6.5 & 6.5 & 6.7 & 6.1 \\
\hline
\end{tabular}




\section{Acknowledgement}

The authors wish to thank Riken Vitamin Oil Co., Ltd., for supplying pollack liver oil.

\section{References}

1) T. Takeuch: in "Fish Culture and Dietary Lipids" (ed. by Japan. Soc. Sci. Fish.), Suisangaku Series No. 22, Koseisha Koseikaku, Tokyo, 1978, pp. 23-42.

2) Y. YONE: in "Fish Culture and Dietary Lipids" (ed. by Japan. Soc. Sci. Fish.). Suisangaku Series No. 22, Koseisha Koseikaku, Tokyo, 1978, pp. 43-59.

3) S. Teshima: in "Fish Culture and Dietary Lipids" (ed. by Japan. Soc. Sci. Fish.), Suisangaku Series No. 22, Koseisha Koseikaku, Tokyo, 1978, pp. 60-77.

4) A. Kanazawa, S. Teshima, and S. Tokiwa: Bull. Japan, Soc. Sci. Fish., 43, 849-856 (1977).

5) A. Kanazawa, S. Teshima, S. Tokma, and H. J. Ceccaldi: Oceanol. Acta, 2, 41-47 (1979).

6) E. G. Bligh and W. J. Dyer: Can. J. Biochem. Physiol., 37, 911-917 (1959).
7) S. Teshima and A. Kanazawa: Bull. Japan. Soc. Sci. Fish., 42, 1129-1135 (1976).

8) T. Mor1 and M. Sugita: in "Shishitsu no Kagaku" (ed. by Nippon Seikagaku Kenkyukai), Tokyokagakudojin, Tokyo, 1974, pp. 19-21.

9) S. Teshima, A. Kanazawa, and H. OKamoto: Mem. Fac. Fish., Kagoshima Univ., 25, 41-46 (1976).

10) T. TAkeuchi and T. Watanabe: Bull. Japan. Soc. Sci. Fish., 44, 733-738 (1978).

11) A. VAN DEN OORD, H. Danielsson, and R. RYHAGE: Nature, 203, 301 (1964).

12) A. VAN DEN Oord, H. Danislson, and R. RYHAGE: J. Biol. Chem., 240, 2242-2247 (1965).

13) W. V. Allen: Comp. Biochem. Physiol., 43B, 193-207 (1972).

14) R. Lester, M. C. Carey, J. M. Little, and S. R. Dowd: Science, 189, 1098-1100 (1975).

15) R. F. Lee and D. L. Puppione: Comp. Biochem. Physiol., 59B, 239-243 (1978).

16) S. Teshima and A. Kanazawa: Bull. Japan. Soc. Sci. Fish., 44, 925 (1978).

17) S. Teshima and A. Kanazawa: Bull. Japan. Soc. Sci. Fish., 44, 1269-1247 (1978). 